\title{
Gênero e violência simbólica em eventos esportivos universitários paulistas*
}

\author{
Miqueli Michetti** \\ Sofia Leonor Von Mettenheim***
}

\section{Resumo}

A partir de pesquisa de campo realizada em eventos esportivos de faculdades do Estado de São Paulo, este artigo busca compreender como neles são construídas e propagadas violências de gênero. Investiga-se as maneiras pelas quais o poder $e$ a dominação simbólicos relativos à desigualdade de gênero são (re)produzidos, bem como a emergência de dinâmicas de resistência à violência por parte de grupos organizados em "coletivos".

Palauras-chave: Violência de Gênero, Violência Simbólica, Eventos Universitários Paulistas, Coletivos Feministas.

" Recebido em 21 de abril de 2017, aceito em 21 de fevereiro de 2019.

** Professora do Departamento de Ciências Sociais e do Programa de PósGraduação em Sociologia do Centro de Ciências Humanas, Letras e Artes da Universidade Federal da Paraíba (DCS e PPGS - UFPB). João Pessoa, PB, Brasil. miquelimichetti@gmail.com / https://orcid.org/0000-0003-2236-5126.

*** Mestranda no Programa Multidisciplinar de Pós-Graduação em Cultura e Sociedade do Instituto de Humanidades, Artes e Ciências Professor Milton Santos da Universidade Federal da Bahia (IHAC - UFBA). Salvador, BA, Brasil. sofiamettenheim@gmail.com / https://orcid.org/0000-0002-7957-9929. 
Gender and Symbolic Violence at University Sports Events in São Paulo Brazil

\begin{abstract}
Based on field research conducted at university sporting events in São Paulo state Brazil, the article analyses how gender violence is constructed and propagated at these events. It shows how symbolic power and domination related to gender inequality are (re)produced and how dynamics of resistance to violence emerge at these events among student groups organized in "collectives".
\end{abstract}

Keywords: Gender Violence, Symbolic Violence, University Sports Events In São Paulo, Feminist Collectives. 


\section{Introdução}

A emergência de coletivos feministas de mulheres estudantes é algo recente no Brasil. Esse fenômeno social, que recoloca o debate acerca do chamado "pós-feminismo" (Scharff, 2012; McRobbie, 2009), não é restrito ao ambiente escolar ${ }^{1}$ ou ao âmbito universitário, manifestando-se também no ensino médio. ${ }^{2}$ No entanto, tal como levanta Carolina Ferreira (2015), diversas autoras têm apontado para "a importância da universidade como um lócus de atuação privilegiada" de movimentos feministas surgidos recentemente no país. Além disso, a pesquisa "Violência Contra a Mulher no Ambiente Universitário" (2015) atenta para a relevância da violência de gênero nas universidades ao levantar um primeiro panorama quantitativo identificando que $67 \%$ das estudantes universitárias afirmaram já ter sofrido algum tipo de violência cometida por um homem na universidade ou em festas acadêmicas, sendo que $52 \%$ das mulheres declararam já ter sofrido agressões morais ou psicológicas e $56 \%$ afirmam ser vítimas de assédio sexual. Já $11 \%$ das estudantes declararam ter sofrido violência sexual, percentual que salta para $28 \%$ quando são incluídos os tipos "ser tocada sem consentimento" e "ser forçada a beijar veterano".

Pesquisas como essas concorrem para a visibilidade do assunto no campo universitário. Contudo, um estopim para que o tema entrasse em pauta nas universidades e na mídia no estado de São Paulo em 2015 foi um inquérito civil público instaurado a partir de relatos de violação e agressão direcionadas especificamente às mulheres $e$ aos homossexuais. Pela primeira

\footnotetext{
$1 \mathrm{O}$ website http://www.mamu.net.br/ busca mapear os coletivos feministas no território nacional. Não se trata de um levantamento completo, mas é elucidativo de como os coletivos são uma realidade plural no Brasil contemporâneo.

2 Algumas notícias recentes servem de exemplo do fenômeno: http://emais.estadao.com.br/noticias/comportamento,como-os-coletivosfeministas-mudam-colegios-de-elite,70001726071 e ainda http://www1.folha.uol.com.br/cotidiano/2015/11/1701071-meninas-formamcoletivos-feministas-em-escolas-de-ensino-medio-de-sp.shtml.
} 
vez, o desrespeito aos direitos humanos em trotes, festas e eventos esportivos universitários foi abordado juridicamente como fenômeno sistêmico. A partir de uma denúncia feita por estudantes da Faculdade de Medicina da USP, a promotora de Justiça de Direitos Humanos e Inclusão Social do Ministério Público do Estado de São Paulo instaurou o inquérito para investigar casos de violação de direitos humanos na Faculdade de Medicina da USP. Com o objetivo de investigar denúncias de outras universidades estaduais, o deputado estadual Adriano Diogo, presidente da Comissão de Direitos Humanos da ALESP propôs uma CPI que, uma vez instalada, colheu cerca de 9 mil relatos e documentos de denúncia e realizou 37 audiências sobre o tema em 7 universidades paulistas. ${ }^{3}$ Foram levantadas suspeitas de 112 estupros ocorridos apenas na Universidade de São Paulo nos últimos dez anos (Relatório, 2015).

Diante dessa conjuntura, a pesquisa que apresentamos neste artigo tomou como objeto a violência de gênero em eventos esportivos universitários paulistas, tendo como foco a violência simbólica perpetrada nesses espaços sociais.

\section{Base teórica, corpus e metodologia da pesquisa}

Neste trabalho, tomamos o conceito de gênero no sentido dado a ele por Joan Scott. Para a autora, gênero é uma categoria analítica que não se refere às diferenças biológicas ou físicas, mas ao saber que estabelece sentido a essas diferenças - $e$ assim também as constrói. Logo, esse saber, no sentido foucaultiano, é sempre relacional e seu significado é não somente produto de uma constante disputa política, mas o próprio instrumento de construção de relações de dominação e subordinação (Scott, 1988). Compreendendo o discurso como algo indissociável da organização social, Scott concebe gênero como um discurso de

3 Universidade de São Paulo (USP), Universidade Estadual de Campinas (Unicamp), Universidade Estadual Paulista (Unesp), Universidade Federal de São Paulo (Unifesp), Pontifícia Universidade Católica de São Paulo (PUC-SP) e de Campinas (PUCCampinas), e Faculdades Adamantinenses Integradas (FAI). 
diferença dos sexos, ou como a "organização social da diferença sexual" (Scott, 1998:15). Heleieth Saffioti é também referência importante por pensar a violência a partir da articulação entre as noções de gênero e patriarcado. Para ela, as normas modeladoras dos homens $e$ mulheres são permeadas por uma desigualdade social que compõe a tradição cultural $e$ as estruturas de poder, o que faz com que a violência de gênero caminhe majoritariamente na direção do homem contra a mulher (Saffioti, 2015).

Já o termo violência simbólica é apreendido no sentido de Pierre Bourdieu (1990, 2002, 2007), para quem ela seria a manifestação do poder simbólico, que conquista sua legitimidade a partir do reconhecimento social do capital simbólico acumulado pelo agente com posição social privilegiada. Nessa concepção, as mulheres não são machistas, mas sim reprodutoras de machismo, pois o machismo seria um sistema de dominação patriarcal. E é preciso destacar que, como aponta Scott (1998) ao retomar o próprio Bourdieu, colocar em destaque a violência simbólica não significa minimizar ou esquecer suas outras faces, em que as mulheres são espancadas, violentadas ou exploradas, e também não significa uma justificativa ou uma "desculpa" para homens que cometem essas violências. Ao contrário, a violência simbólica pode ser entendida como aquela que fundamenta as faces mais visíveis da violência de gênero.

Mas se a dominação só é possível enquanto os dominados operam a partir das categorias dominantes, as mulheres possuem um papel crucial na subversão dessa dominação a partir da tomada de consciência dessa violência simbólica e das disputas sobre as categorias legítimas. Isso nos leva além do diagnóstico bourdieusiano sobre a dominação de gênero, de que "as mulheres não podem senão confirmar seguidamente tal preconceito" (Bourdieu, 2007:53). Nesse sentido, tal como Terry Lovell (2000; 2004), procuramos trabalhar "com e contra" Bourdieu, levando ainda em consideração as reflexões de Lois McNay (1999; 2000; 2004) acerca do lugar da agência na teoria feminista inspirada no legado bourdieusiano. 
Nessa direção, ainda que traga mais contribuições empíricas que teóricas, este artigo converge com a busca de Lisa Adkins (2004:5) por uma "renewed relationship between feminist and social theory". Além do diálogo com Bourdieu, o legado foucaultiano sobre as relações entre saberes, discursos e poder também é um dos pilares de sustentação deste trabalho. Assim, entretecemos dois fios complementares: com Bourdieu (2002), buscamos perceber como as disputas simbólicas dentro de um determinado espaço social passam pelo acúmulo desigual de capital simbólico por agentes em diferentes posições; com Foucault, tentamos apreender as recorrências discursivas, suas superfícies de emergência $e$ as formas pelas quais o poder é disputado a partir de discursos ligados a determinadas posições de sujeito no universo que analisamos (Foucault, 1979; 2008). Diante disso, é relevante lembrar que os discursos são práticas sociais em Foucault $e$ que as classificações são parte da construção do mundo social em Bourdieu.

Essas concepções foram tanto pontos de partida como lugares de chegada do trabalho que expomos a seguir, que se debruçou sobre as disputas simbólicas ou discursivas em torno da violência de gênero (re)produzida em eventos esportivos organizados por estudantes de instituições de ensino superior paulistas. A pesquisa, que durou 18 meses $^{4}$, compreendeu os seguintes eventos:

1) Economíadas, encontro de 8 faculdades que possuem curso de Economia na cidade de São Paulo (ESPM, Fecap, PUC, USP, FGV, Mackenzie, Insper e Faap). O evento foi escolhido devido ao maior acesso das pesquisadoras ao campo, visto que possuem vínculos com uma dessas instituições. Por isso, essa fase da pesquisa foi a mais marcada pela posição das pesquisadoras no campo.

\footnotetext{
4 A pesquisa se deu no âmbito de uma iniciação científica realizada entre 2015 e 2016, na EAESP-FGV, com recursos do CNPq e do GVpesquisa. Ambas as autoras participaram em todas as fases da pesquisa, da concepção à redação final.
} 
2) Calomed, competição entre calouros dos cursos de medicina da Faculdade de Medicina da USP, Santa Casa, Faculdade de Medicina de Jundiaí e Faculdade de Medicina de Sorocaba. A escolha desse evento se deu porque a medicina se destaca no debate público sobre a questão da violência nas universidades, principalmente devido à CPI na ALESP. Esse evento específico foi escolhido por ser menor que o Intermed (principal evento esportivo da área), e por isso apontado pelos alunos da Atlética da FMUSP como um espaço no qual haveria maior acesso às dinâmicas sociais. Além disso, por ser uma competição entre calouros, possibilitava o enfoque nas relações hierárquicas que têm lugar nas faculdades e atléticas.

3) JUCA (Jogos Universitários de Comunicação e Artes), evento que reúne PUC - São Paulo, Anhembi Morumbi, Belas Artes, Cásper Libero, ECA-USP, Mackenzie, Metodista e PUCCampinas. Foi escolhido devido à hipótese de que nele haveria maior presença de alunas e que isso poderia implicar em alguma alteração das relações de gênero no evento.

Além da participação nos eventos, observamos as disputas entre Atléticas e Coletivos antes e depois deles, bem como os posicionamentos das instituições de ensino. Ademais, foram realizadas entrevistas com representantes dos diferentes grupos de alunos concernidos (como atléticas, baterias, coletivos identitários e times esportivos).

Para expor alguns dos principais resultados dessa pesquisa, a sequência deste artigo se divide em duas partes principais. A seguir apresentaremos as dinâmicas de violência simbólica que se (re)produzem nos eventos investigados. Depois, passaremos à análise das recorrências discursivas que identificamos em tais dinâmicas e das disputas simbólicas de resistência e reação em andamento entre agentes no espaço social abordado. Finalizaremos com algumas reflexões sobre a imbricação entre transformações discursivas e mudanças práticas. 


\section{Produção simbólica e violência de gênero nos eventos esportivos universitários}

Os eventos esportivos universitários acima referidos acontecem uma vez por ano durante feriados em cidades do interior do Estado. São eventos organizados pelas atléticas das faculdades e aguardados pelo alunato, o que pode ser percebido pelas "contagens regressivas" que antecedem os eventos tanto em páginas em redes sociais quanto estampadas nas próprias faculdades. Eles são construídos e percebidos como um "mundo paralelo" em relação tanto à cidade que sedia o evento quanto ao cotidiano dos alunos.

A observação nos eventos nos levou a discernir três espaços principais de convívio nos quais a violência simbólica se (re)produz: alojamentos, jogos e festas, sendo que os ônibus de deslocamento dos participantes funcionam também como uma espécie de antecâmara para todos esses espaços.

\section{Músicas}

Os "hinos" e "gritos de guerra" das torcidas e as letras das músicas cantadas pelas baterias são a instância mais evidente de produção simbólica violenta dos eventos. Por serem o principal objeto do debate sobre gênero que se dá nos próprios eventos, é a partir dele que o debate mais amplo sobre violência de gênero vem à tona. As "baterias" das faculdades assumem papel central, mas não exclusivo, na invenção e na propagação dessa produção simbólica. Recentemente, os discursos misóginos que constituem suas letras vêm sendo questionados e vetados, seja pelos coletivos feministas, pelas atléticas, pelas instituições de ensino e, no caso da medicina, pelo poder público.

As primeiras recorrências discursivas observadas na pesquisa vêm das próprias músicas cantadas por baterias e alunos, as quais muito comumente circulam entre faculdades com pequenas alterações. 
A objetificação sexual da mulher:

A mulher não é referida nos cânticos como sujeito que pratica os esportes, mas como um objeto sexual a ser utilizado. "Nosso esporte é na vagina", dizia o hino da FGV. As letras evocam relações sexuais e as mulheres aparecem como fonte de prazer masculino: "Se for Feana eu posso até botar pra dentro; Mas vou tapar seu rosto com um cobertor". Ainda nessa lógica, uma faculdade poderia "possuir" as alunas de outras: "A xoxota do Mackenzie é nossa". A partir dessa metonímia, a mulher é reduzida ao seu órgão sexual, reforçando seu papel de objeto sexual.

Exaltação da violência sexual e apologia ao estupro:

$\mathrm{O}$ recurso às imagens de coerção sexual é utilizado como suposta demonstração de poder de determinada faculdade. Em trechos como "Eu sou pró na arte de arrombar vadias, alargo todo mundo", a capacidade de submeter mulheres de outras instituições ao sexo através da violência parece construir o sentimento de supremacia entre os alunos.

Discurso da honra:

Aparece nas músicas a compreensão de que degradar a imagem das mulheres da instituição rival afeta a "honra" dos homens que lá estudam. Assim, a sexualidade da mulher é evocada com o intuito pressuposto de insultar a "honra" daqueles que "possuem tais mulheres". As alunas são geralmente retratadas como "vadias", "vagabundas", ou "putas", com menções à prostituição, como em "nem de graça eu te quero". A sexualidade ativa da mulher é enunciada como algo que negaria seu valor. A prostituição aparece como o auge de sua coisificação - $e$ no caso do "nem de graça", de desdém pela "coisa" ou "mercadoria" desvalorizada. O título da música da FGV que se refere ao Mackenzie como "Facul de Puta" é exemplar dessa recorrência. 
Controle da aparência a partir de padrões de beleza:

Um bom exemplo é a música "Cala a boca Bigoduda, vem servir meu café". A outra face da objetificação feminina se coloca quando os corpos femininos não seguem os padrões estéticos estabelecidos socialmente e passam do lascivo para o indecente, indesejável, sem valor. "Bigoduda" aparece como um símbolo de mulher feia. "Baleia" e "gorda" são termos comuns. Novamente insultar a aparência das alunas de dada faculdade passa a ser um instrumento para atacar a instituição.

Discriminação de classe:

Como no trecho acima, muitas músicas fazem menção à figura de "empregada", seja com relação à aparência, como em "cara de filha de empregada", ou à função que essas exerceriam: "vou te contratar, você vai ser minha empregada". A discriminação do trabalho doméstico, visto como menos digno, é utilizada para inferiorizar as alunas de outros cursos, de faculdades consideradas menos "de elite", e afirmar que elas estariam lá para servir.

Em conversas e entrevistas, foi possível perceber que os termos parecem não remeter ao seu significado original para seus enunciadores, possivelmente por conta da repetição e dos novos sentimentos que são associados com a experiência dos jogos. Além disso, muitas músicas são paródias de músicas populares já existentes, com as quais os alunos já possuem vínculos. Ao mesmo tempo, esse esvaziamento do significado pode estar ligado à naturalização do conteúdo: o evidente se torna invisível. Apesar de as críticas às músicas serem recorrentes, é apenas recentemente que elas ganharam força dentro das universidades, capitaneadas por "coletivos de mulheres".

\section{Alojamentos}

Escolas públicas das cidades sede costumam funcionar como "alojamentos" para os participantes dos eventos. A grande quantidade de participantes, todos querendo se movimentar nos 
mesmos horários, gera desafios para a logística: filas para comer, filas para os banheiros e filas de alunos esperam os ônibus para ir a festas e jogos. $\mathrm{O}$ alojamento é um espaço de descanso, de festa, mas também de arrumar-se para as festas. É possível perceber a diferença da importância dessa atividade para os alunos $e$ as alunas nos tamanhos das respectivas malas: enquanto as alunas discutem se trouxeram roupas suficientes para as festas, maquiagens, secadores de cabelo e sapatos de salto alto, os meninos levam malas menores e, despreocupados, parecem estar indo para outro destino. Durante os eventos, isso significou um investimento de tempo nas aparências extremamente diferente: os banheiros reservados às alunas tinham longas filas para o banho, os poucos espelhos eram disputados e também geravam filas para a aplicação de maquiagem. As tomadas eram disputadas para o uso de secadores e chapinhas, que chegavam a sobrecarregar a rede elétrica causando quedas de energia. Quanto aos alunos homens, muitos não tomaram banho durante os vários dias do evento. Nesse espaço ficou particularmente evidente a "necessidade de investimento no trabalho de apresentação como objeto estético" mencionada por Bourdieu (2007:138) e uma das faces naturalizadas da violência simbólica. Enquanto as alunas buscam a perfeição na sua apresentação normalizada em torno dos padrões de beleza existentes, os alunos não investem o mesmo tempo ou energia em sua apresentação e o próprio desleixo parece ser valorizado.

\section{Jogos}

Durante os jogos, é comum que a torcida insulte os jogadores e existem várias táticas para realizar tais ofensas, como torcedores ficarem à beira da quadra chamando os jogadores pelo nome em uma tentativa de distração. Contudo, os xingamentos aos alunos geralmente se referem à forma de jogar, como "lerdo" ou "perna de pau". Além disso, aparece o xingamento "corno" e muitas vezes namoradas e mesmo mães são insultadas, dentro da lógica de que isso feriria a honra dos alunos "possuidores" das 
mulheres ofendidas. Também é comum que os jogadores sejam chamados de "viado", visto que a homossexualidade é considerada ofensiva. Já os xingamentos às alunas se referem mais frequentemente a aspecto físico de seus corpos ("gorda", por exemplo), mas também à incapacidade intelectual ("burra") e à sexualidade ("vadia").

O corpo da mulher aparece como objeto estético, enquanto o (corpo do) homem é visto como realizador de atividades. Sobre isso, uma aluna da Cásper Lîbero explicita que

\begin{abstract}
Aluno homem a galera não xinga, xinga a forma como joga. Ou a namorada, também é clássico. Já as meninas, é sobre elas, seu corpo, tipo, gostosa ou gorda, sua vida sexual, falando para rebolar. Quando elas ganham os jogos, as pessoas dizem - ah, não é mais que obrigação, mas quando perdem - é por que é mulher mesmo.
\end{abstract}

As mulheres também são vistas como menos aptas a contestar e a reagir a essas ofensas. Em brigas de torcidas, é comum que os alunos se envolvam para "defender" as alunas. Além disso, discursos que caracterizam as mulheres como corporalmente incapazes de realizar certas funções aparecem como justificativa para o pequeno número de mulheres tocando instrumentos mais pesados na bateria e para a inexistência de times femininos de futebol de campo.

\title{
As Festas
}

Geralmente ocorrem três ou mais festas durante os jogos, sendo que a primeira e a última são feitas pelas faculdades para seus respectivos alunos, e uma delas reúne todas as faculdades que compõem os jogos. Com preços que variam entre 80 e 150 reais, algumas também são abertas para moradores da cidade sede.

A contratação recorrente de atrações musicais populares que trazem letras com apologia ao estupro e misoginia é um padrão verificado nos eventos universitários em geral, e não somente nos 
jogos. Elas parecem constituir o imaginário cultural dos alunos, e a construção do que chamaríamos de identidades universitárias também é marcada por esse tipo de representação.

O ponto mais recorrente nos relatos das alunas com relação às festas foi o assédio sexual. Para combatê-lo durante o JUCA, a Atlética da PUC disponibilizou o "Whatsapp" de duas alunas da Atlética que eram parte da organização do evento, para que as vítimas pudessem denunciar ou pedir apoio. A aluna nos informou que "a ideia era criar um canal informal, mais próximo dos meios de comunicação dos alunos no dia-a-dia", indicando que ela detinha "autoridade para tirar pessoas da festa", mas considera ainda que

[...] o grande problema está no momento entre a pessoa sofrer o assédio e tomar a decisão de denunciar [...]. A primeira reação da pessoa não é pegar o celular para denunciar. Esse meio termo é o mais difícil. É frustrante por que eu fico sabendo dos casos depois, tenho autoridade... mas se não me avisarem na hora, não tem o que eu fazer. Queria poder fazer mais...

Uma membra da Frente Feminista e LGBT do JUCA relatou que a frente recebeu muitas denúncias de alunas, que queriam relatar as situações de assédio pelas quais passaram. Entretanto, a maioria não queria que os casos fossem levados para a atlética ou denunciados formalmente.

Um aspecto importante sobre os relatos é que neles a maioria dos assédios é classificada como "comuns" e "já esperados". A linha que separa os "assédios normais" dos "assédios denunciáveis" para as alunas é difícil de delinear e mereceria investigação futura, pois apesar das alunas reconhecerem nominalmente as situações como "assédio" $e$ "violência", as denúncias raramente se concretizam.

Foi possível perceber que, quando presentes, os coletivos impõem certa intimidação às manifestações mais explícitas de violência de gênero. Uma aluna da bateria da FGV colocou que 
considerava tal presença "importante principalmente no momento que a gente está, para colocar uma pressão do tipo, olha o espaço não está livre para você voltar a ofender as mulheres. E também como forma de apoio, acho importante".

A partir do levantamento do repertório simbólico composto pelas músicas, pelo material publicitário dos eventos, pela programação musical contratada, pelas ofensas das torcidas $e$ pelos assédios nas festas, podemos perceber algumas regularidades discursivas mais gerais. Além da normatização do corpo feminino a partir de padróes de beleza estatuídos, elas operam uma objetificação sexual das mulheres na qual a sexualidade feminina ativa é concebida como um "atentado à honra" daqueles que a "possuem", sendo considerada indecente quando não está a serviço dos homens e/ou não é controlada por eles. Em um contexto de competição entre as faculdades, descrito pelos alunos como "guerra", abundam enunciados de exaltação da violência e coerção para a obtenção de sexo como demonstração do poder masculino. A mulher seria um instrumento para atacar a dignidade dos rivais, seja através da apologia ao estupro de alunas de outras faculdades, ou da sua suposta difamação como "putas" ou "vadias". Tais padrões discursivos reproduzem o saber da mulher como objeto, em oposição ao homem agente.

\section{Resistências e reações: as disputas simbólicas em torno da violência de gênero}

As dinâmicas de violência simbólica que descrevemos serão alvo de crítica e resistência antes, durante e depois dos jogos. Como demos a ver brevemente acima, um agente crucial das disputas simbólicas que atualmente se travam nesse espaço social são os Coletivos Feministas. Em boa medida, eles serão construídos em oposição relacional às Attéticas, de maneira que é importante que nos detenhamos sobre esses dois agentes.

As atléticas universitárias podem ser consideradas como superfícies de emergência dos discursos imbuídos de violência de 
gênero $e$, nesse sentido, são importantes para se compreender como esses discursos se consolidam e se reproduzem dentro das entidades $e$ ambientes universitários. O funcionamento destas parece permitir que agentes de difusão ocupem lugares de sujeito $e$ acumulem poder simbólico que legitimam esses discursos violentos. De acordo com integrantes do Coletivo Yabá, coletivo feminista do curso de Direito na PUC, o surgimento dessas instituições remontaria à ditadura militar, quando esses clubes recreativos e esportivos foram criados como combate às organizações políticas estudantis (como grêmios, diretórios, centros acadêmicos e a própria UNE) e com o objetivo de "esvaziamento político da sociabilidade entre os universitários". As atléticas possuem seu próprio sistema de recrutamento e operam como um espaço fechado de circulação de "tradições", o que permite o fortalecimento de símbolos violentos e o silenciamento de violências (não só) de gênero. Atuando em uma estrutura hierárquica militarizada, os "veteranos" se constituem como autoridades inquestionáveis, que reproduzem discursos e práticas violentas.

Os eventos esportivos são um espaço de poder das atléticas, que concebem e produzem os eventos como celebrações ao final de longos períodos de dedicação e esforço em treinos. Os eventos são concebidos a partir de estruturas hierárquicas e de saberes discriminatórios e são parte da reputação das atléticas, que, por isso, buscam cercear críticas. Isso é notável inclusive na dificuldade (e em alguns casos impossibilidade) de inserção como pesquisadoras no campo $^{5}$, mas também nos casos de assédio

${ }^{5}$ Um exemplo dessa dificuldade se deu durante entrevistas com integrantes da Atlética da FMUSP, os quais indicaram que a realização da pesquisa em determinados espaços poderia significar risco à integridade das pesquisadoras, $e$ que haveria um sistema coercitivo de identificação do pertencimento à organização. 
relatados às membras coletivos feministas que frequentaram os eventos. ${ }^{6}$

O panorama antes do surgimento de grupos que questionassem as práticas e representações correntes era de naturalização da violência de gênero, pois os saberes que embasavam os discursos não concebiam diversas violências enquanto tal. É importante ressaltar que ainda há espaços em que esse saber é o único existente, devido à ausência de grupos engajados nesse questionamento, ou ao pouco capital simbólico $e$ legitimidade que possuem. Essa naturalização reproduz e fomenta práticas também violentas, como assédios e estupros que não são reconhecidos como tal, a impunidade de agressores, a culpabilização das vítimas e o funcionamento de mecanismos institucionais de silenciamento dessas vítimas.

\section{Resistências}

A organização de grupos de mulheres e outras minorias políticas, como Coletivos e Frentes feministas, LGBT e negros, trouxe novidades a esse cenário de invisibilização. Nesse sentido, a concepção de Terry Lovell (2004) sobre os movimentos sociais feministas como atores em um dado campo nos parece consequente, já que estamos em face de uma disputa de práticas e representações que tem levado a uma alteração do equilibrio de forças vigente. A partir do acúmulo de capital simbólico, tais grupos disputam os saberes postos e, com campanhas, mobilizações, manifestações, grupos de estudo, dinâmicas de acolhimento e estratégias de segurança em eventos, passam a problematizar a violência de gênero no meio universitário.

As principais recorrências discursivas identificadas no caso dos coletivos foram a utilização de depoimentos de vítimas de violência, as denúncias de machismos na universidade através de

\footnotetext{
${ }^{6}$ Nos eventos da FMUSP, o coletivo feminista da faculdade não se faz presente, devido ao assédio sofrido por suas integrantes em anos anteriores, situação que, longe de ser singular à FMUSP, é comum em eventos no interior do Estado.
} 
"notas de repúdio", e a enunciação da existência de uma "cultura de violência de gênero". Outra recorrência é o uso de terminologia acadêmica dos estudos de gênero, o que nos leva a reiterar "a necessidade de se entender a recepção da produção de conhecimento teórico das universidades nos movimentos feministas" (Ferreira, 2015:216).

Para compreender como as disputas simbólicas vêm ocorrendo, é importante ressaltar que, para muitas alunas entrevistadas, o principal motivo do surgimento dessas organizações, e de maior inserção do feminismo no meio universitário, está relacionado às redes sociais. Diante disso, nosso trabalho confirma o argumento de Carolina Ferreira (2015:222) de que "a atuação de coletivos feministas por meio das redes digitais tem ampliado as semânticas e gramáticas políticas referentes a noções de violência". Além de dar visibilidade à pauta $e$ legitimidade às ações dos coletivos, o "ativismo via redes sociais" também influenciou a forma desses grupos se mobilizarem. As denúncias e "notas de repúdio" nas redes sociais tornaram-se formas de chamar atenção para as causas do "novo feminismo". Com baixo investimento de energia e grandes ganhos de visibilidade, tornou-se comum travar "batalhas" virtuais, com memes, referências acadêmicas, mas principalmente troca de ofensas e uma grande audiência. Em meio à estigmatização e ao desinteresse com relação às pautas feministas, as batalhas virtuais foram utilizadas para tornar a violência de gênero "o assunto" no cotidiano das faculdades. Entretanto, ficou patente que a conscientização da "audiência" compete com dinâmicas de rivalidade e exibicionismo no meio virtual, algo que apresenta elementos inéditos com relação ao trabalho sobre "ciberfeminismo" de Montserrat Boix e Ana de Miguel (2013) e continua as discussões de Carolina Ferreira (2015) sobre "feminismos na web".

Buscando romper com estereótipos feministas atribuídos à geração passada, o autointitulado "novo feminismo" teria transformado a própria "atitude de ser feminista", apresentando-se como "descolado", bem-humorado e com um forte caráter virtual, 
de forma que os resultados desta pesquisa convergiram com os trabalhos de Laura França Melo (2012), Eliane Gonçalves e Joana Plaza Pinto (2011) e Karla Galvão Adrião e Ricardo Pimentel Méllo (2009). O feminismo passou a aparecer na mídia, na moda, na música pop e também nas faculdades de elite. Essa "gourmetização do movimento" elitizou certas bandeiras, pois foi apropriado por uma parcela de mulheres que estavam em posições de poder e que defendem correntes feministas liberais $e$ capitalistas, tal como observado em estudos anteriores por autoras como Tania Modleski (1991), Angela McRobbie (2004), Emilie Zaslow (2009), Christina Scharff (2014) e Michelle Lazar (2014).

$\mathrm{O}$ recorte de classe é fundamental para compreender a velocidade com que esses discursos se propagaram nas universidades analisadas. Nos espaços estudados, muitas alunas que compõem os grupos feministas já possuem um acúmulo de capital simbólico devido à presença de outros capitais reconhecidos. Diante disso, e com todas as contradições implicadas na elitização das bandeiras, ainda que haja força nas reações conservadoras que visam a barrar esses discursos, esses movimentos feministas universitários possuem - a depender da posição social da faculdade em questão - oportunidades de visibilidade, com cobertura na mídia tradicional inclusive, recursos financeiros para bancar campanhas e eventos e tempo disponível para a auto-organização.

\section{Discursos e práticas}

A formação e a circulação desse grupo de discursos de reconhecimento e resistência à violência fazem com que as práticas sejam transformadas, trazendo mudanças nos próprios discursos. Partindo do pressuposto foucaultiano de que as práticas se fazem de acordo com saberes ou com discursos socialmente considerados verdadeiros, foi possível identificar uma série de novas práticas que surgem em decorrência da maior visibilidade de novas bandeiras. A partir das premissas de Bourdieu, mas com uma conclusão que, em certo sentido, o ultrapassa, foi possível 
verificar que as categorias mentais ou representações desenvolvidas pelos novos sujeitos mobilizadores permitem que eles transformem práticas sociais a partir de um novo horizonte simbólico. Para colocar como o próprio autor, a mudança nas coisas da lógica implica em mudanças na lógica das coisas (Bourdieu, 1990). E, pensando na concepção foucaultiana retomada por Fairclough (2001) de que discursos são práticas sociais, podemos conceber, de acordo com o que a imersão em campo nos mostrou, que mudanças nas práticas impulsionam mudanças discursivas. É importante apontar, no entanto, que esses discursos avançam e recuam nas diferentes instituições de forma não linear, trazendo mudanças e permanências nos ciclos de eventos universitários.

À medida que os discursos feministas ganharam visibilidade e legitimidade, as práticas vigentes nos jogos universitários também se alteraram. Um aspecto fundamental para permitir essas novas práticas é a mudança na cultura organizacional de entidades como atléticas e baterias universitárias. Essas entidades foram nesse período ocupadas por mais mulheres, e por mais mulheres feministas. As relações entre coletivos e atléticas podem ser de conflito, tensão, negociação ou colaboração. A violência de gênero "de repente" virou pauta e essas organizações foram pressionadas a realizar ações para combatê-la sem nenhuma experiência no assunto. Apesar de muitos alunos dessas entidades tomarem parte nos discursos da reação, que abordaremos mais adiante, eles não tiveram muita escolha. Ou ainda, dependendo da posição de poder e do respaldo institucional dos coletivos nas respectivas universidades, as atléticas e baterias perderam a hegemonia da construção da visão de mundo, para falarmos como Bourdieu. Assim, certos discursos e práticas foram desnaturalizados e considerados machistas, deixando de ser aceitos, e surgiu a necessidade de se repensar os jogos universitários.

Mudanças são notáveis no material de divulgação do evento nas redes sociais, do qual é exigido maior inclusão e diversidade, na contratação da programação musical, que deve dar espaço à 
maior representatividade e vetar atrações discriminatórias, na organização da segurança e na necessidade de criação de canais de denúncia para violências de gênero ocorridas nos eventos, mas, principalmente, nas novas músicas entoadas pelas baterias $e$ torcidas universitárias, nas quais se busca reconstruir as identidades universitárias a partir do que "ainda pode" ser enunciado.

As mudanças observadas durante a pesquisa se deram nas organizações de cada universidade em tempos e intensidades diferentes. Essa observação é importante, pois tais mudanças não ocorrem de forma linear, mas sim através de avanços e retrocessos constantes, compostos por experimentações e disputas de forças. Podemos dizer que essas dinâmicas podem ser compreendidas como jogos de ação $e$ reação, disputas por saberes $e$ representações, baseados nas posições que os diferentes agentes $e$ instituições ocupam nesse campo.

Assim, a presença dos coletivos implica em disputas que se ligam também a mudanças nos eventos e no ambiente universitário mais amplo. Se os coletivos de mulheres e minorias políticas possuem papel chave em reconhecer e desvelar como tais as violências sofridas, também é importante perceber que esse papel incomoda. Em muitos casos, a expressão "os incomodados que se retirem" é utilizada para sugerir que esses grupos deixem de frequentar os jogos universitários. E quando os "incomodados" escolhem ocupar esses espaços, o discurso passa a ser "os incomodados que se mobilizem". Diante do enunciado de que "as feministas só sabem reclamar, mas não fazem nada", é atribuída às próprias feministas a responsabilidade de combater a violência de gênero nos eventos.

Para as atléticas, parece ser vantajoso estabelecer uma relação de "colaboração" com os coletivos, pois eles passam a ser responsáveis por executar essas mudanças: o trabalho é delegado; a responsabilidade pública parece ser assumida e a resistência passa a "ser parte" da construção do evento (mesmo que sem protagonismo ou sem estrutura para efetivar suas demandas), inibindo as críticas. Essa é uma solução sem custo financeiro para 
as atléticas e que sobrecarrega as alunas e alunos membros desses coletivos, além de não gerar necessariamente acolhimento de vítimas ou encaminhamento de qualidade para os casos de violência. Em face dessa situação, resta aos grupos organizados as opções de boicotar, visando a não apoiar um evento com símbolos e práticas de violência de gênero, ou de participar criticamente, com o objetivo de colaborar na construção de um evento menos violento. Esse dilema foi assim enunciado por uma aluna do coletivo da Cásper Líbero:

\begin{abstract}
A gente debate se deveria marcar presença massiva ou deveríamos boicotar o evento. Algumas pessoas que foram não querem financiar e compactuar esse tipo de evento, por entender que toda a sua lógica é calcada em opressões. Mas praticamente qual seria o efeito disso? Isso prejudica muito as atletas mulheres, que ficariam ainda mais vulneráveis. Eu, pessoalmente, sou favorável a qualquer ocupação de espaço.
\end{abstract}

Enquanto a segunda opção parece trazer resultados mais efetivos para o caráter do evento, a longo prazo essa "colaboração" parece dificultar a construção de mecanismos de segurança, denúncia e acolhimento mais institucionais. Ao contrário, por meio do trabalho desses coletivos, os eventos passam a envergar títulos de "mais inclusivos" ou de "respeito à diversidade".

Diante disso, é particularmente relevante o dado de que a grande maioria das vítimas que relatou violências aos coletivos não quis realizar denúncias judiciais formais. A dificuldade da denúncia faz parte da própria dinâmica da violência de gênero, seja pela culpabilização das vítimas que o judiciário reproduz, pelo medo de exposição ou pela falta de estrutura para encaminhar a denúncia. Se os relatos já são uma maneira simbólica de lidar com a violência, a não institucionalização das denúncias tende a levar à impunidade, à ausência de memória dessas violências, e à impossibilidade de aprimorar os mecanismos de escuta e denúncia institucionais. Assim, se os coletivos compõem uma porta de 
entrada de denúncia primordial pela proximidade que possuem com as alunas, eles nem sempre podem acolhê-las, encaminhá-las e garantir o julgamento de agressores. Ao mesmo tempo que denunciar ou não será sempre uma escolha da vítima, é necessário perguntar a que essa escuta vem em termos de mudança social.

\section{Reações}

Em meio à proliferação dos discursos e práticas visando à coibição da violência de gênero, uma série de discursos operou no sentido contrário, compondo uma situação de disputa pela construção dos saberes e narrativas legítimas. Como veremos a seguir, os discursos de reação têm dois sentidos principais: a) desqualificar os discursos dos coletivos feministas, de outras minorias e de simpatizantes, e b) naturalizar ou manter a naturalização sobre as violências de gênero. Senão, vejamos:

Classificação negativa dos agentes que produzem esses discursos, as feministas.

Desde "gordas" a "mal comidas", os insultos caracterizam as alunas como "desocupadas", que, por supostamente não terem "algo melhor a fazer", estariam levantando problemas "insignificantes". Esses discursos não veem o feminismo como político nem os coletivos feministas como organizações políticas, mas como "inutilidades".

Apresentação do "politicamente correto" e da "chatice" como ameaças às "brincadeiras" $e$ ao "senso de humor" na faculdade:

Utilizando-se dos estereótipos de feministas como "chatas" $e$ "implicantes", o discurso apresentado de forma dramática é que o mundo estaria caminhando para um futuro sem graça, no qual todos têm voz para "reclamar" de suas opressões e assim nada seria permitido. Há mesmo uma preocupação desses agentes com uma suposta "escassez de ofensas", que se expressa, por exemplo, na entrevista com um integrante de uma bateria: 
O que eu me pergunto no futuro é como vai funcionar no futuro esse negócio do gênero. Se você não pode mais zoar o cara, você vai fazer o que? Se você não vai zoar o gênero, vai falar - ah, o cara é burro - mas aí vão falar que é por que ele não teve a mesma oportunidade que você na vida $e$ é bolsista...

A expressão "mimimi" é comumente utilizada para se referir às notas de repúdio ou denúncias, imputando-as a pessoas demasiadamente sensíveis, que reclamam sem propor algo no lugar. $\mathrm{O}$ discurso ao mesmo tempo que reduz as violências a brincadeiras, afirmando que elas não possuem efeitos na realidade, também estigmatiza aqueles que o definem como violência, que estariam "exagerando" ou mesmo ficando "loucas".

Concepção da competição e da rivalidade como naturais à ordem do mundo:

As "ofensas" nada mais seriam que uma reprodução natural de tal ordem. Para sustentar esse argumento, exemplos de "bullying" sofridos são comparados às opressões de gênero denunciadas, sob o argumento de que "todos sofrem, e aqueles que reclamam são apenas frágeis demais".

Preservação das "tradições" da faculdade:

$\mathrm{O}$ que se verifica é que muitas vezes as tradições foram construídas recentemente e transmitidas para a próxima geração de alunos já imbuídas do caráter de "tradições". Muitos alunos enunciaram um "sentimento de perda", ligado à construção identitária que ocorre através dos símbolos cultivados $e$ estimulados desde seu ingresso na faculdade. A isso se liga ainda o capital simbólico já acumulado pelos "veteranos". Com influência dentro das entidades e como figuras de autoridade que se colocam como detentores do saber sobre a "genuína" instituição, eles possuem importante capacidade de mobilização do discurso por "lembrarem" dos "bons tempos" na faculdade, antes do "reino da chatice". 
Apropriação de conceitos ligados à resistência:

Termos como "liberdade de expressão" e "censura" são evocados de forma que os enunciadores de discursos de reação aparecem como perseguidos, oprimidos e censurados. Através da caracterização do feminismo como radical e como "nazista", donde o uso do termo "feminazi", os alunos enunciam a mobilização feminista como persecutória - responsável por uma "caça às bruxas" no ambiente universitário.

Apropriação cínica de campanhas, discursos ou estratégias feministas:

Em tom de deboche, frases como "o busão tá me oprimindo" e "não é não", referências a campanhas contra o assédio, são empregadas em situações banais. Um bom exemplo pode ser percebido em uma ocasião em que, diante da utilização, por um coletivo feminista, de apitos para denunciar situações de violência durante os jogos, um grupo organizado de participantes homens também apareceu munido de apitos. Com isso, como os apitos ressoavam o tempo todo, a iniciativa do coletivo foi esvaziada.

As disputas pelas categorias e pelos significados utilizados violências ou brincadeiras, por exemplo - se deram tanto nas redes sociais quanto durante os Jogos. Os discursos de reação atuam buscando a manutenção da situação anterior ao surgimento da resistência, especialmente a partir da tentativa de desqualificar os locutores que a exercem e da defesa de que as violências seriam "brincadeiras" constituintes da experiência universitária. É importante apontar que tais discursos são criados a partir da necessidade de manter um poder simbólico que não era contestado anteriormente, o que indica uma alteração dos jogos de forças no ambiente universitário. 
Considerações finais: ciclos de resistência $e$ reação

A pesquisa revelou três grupos de discursos que perpassam as dinâmicas de gênero nos espaços dos Jogos, mas também nos espaços universitários em geral. $\mathrm{O}$ primeiro grupo seria aquele cujos discursos são compostos pelas normatizações dos papéis de gênero, pelas violências simbólicas e pelas violências mais explícitas como misoginia, apologia a crimes de violência de gênero e assédios. O segundo grupo é composto por discursos de resistência a essas violências, geralmente proferidos por grupos auto-organizados de mulheres e outras minorias políticas, além de alunos apoiadores das respectivas causas. Já o terceiro seriam discursos de reação a essa resistência, que defendem o primeiro grupo de discursos e/ou atacam o segundo.

Trata-se de uma disputa entre a naturalização e o combate à violência. A cada ciclo de eventos universitários, o poder circula entre as atléticas e os coletivos e sua distribuição é influenciada pelas dinâmicas de poder mais abrangentes em torno de gênero na sociedade e também pelas mudanças nas gerações de alunos que compõem as organizações. As novas práticas de um ciclo geram novos discursos, que por sua vez geram novas práticas, constituindo um ciclo que implica em alterações nas posições de poder dos agentes envolvidos.

Se o movimento no sentido de reprodução das violências de gênero se mantém, há também espaço para a construção de resistência à violência. As mobilizações recentes esboçam a implementação autônoma de práticas que acolham e protejam as mulheres nas universidades. Esse processo passa por reconhecer, desnaturalizar e questionar saberes violentos e construir novos saberes que contemplem os direitos da mulher e que incluam o desfrute da educação e da experiência universitária sem medo ou violência.

Ainda que não devamos negligenciar o viés de classe dos processos sociais analisados neste artigo, é possível aventar que a construção de novos saberes e práticas no ambiente universitário, considerado como um espaço político em si, pode servir como 
ensaio para uma nova geração adentrar a arena expandida de disputa política, pela construção de um leque mais amplo de direitos para as mulheres. Diante disso, nos somamos aos esforços dos trabalhos congregados por Adkins e Skeggs que colocam "the issues of social change, of social reproduction and the rethinking of classificatory systems as central to the concerns of contemporary feminism" (Adkins, 2004:10, grifos nossos). Afinal, se Bourdieu está certo ao afirmar que a violência simbólica é justamente aquela cuja legitimidade é automaticamente aceita e que a naturalização da violência ocorre através da transformação das relações sociais de força em irreconhecíveis (Bourdieu, 2010:61), a pesquisa aqui apresentada revelou, "com e contra Bourdieu" (Lovell, 2000), que quando as mulheres passam a reconhecer a violência enquanto tal, o pilar que a sustenta começa a ruir.

\section{Referências bibliográficas}

ADKINS, Lisa. Introduction: Feminism, Bourdieu and After. In: ADKINS, Lisa; SkEGGS, Beverley (ed.). Feminism After Bourdieu. Oxford, The Blackwel Publishing/The Sociological Review, 2004, pp.3-18.

ADRIÃO, Karla Galvão; MÉLlo, Ricardo Pimentel. As jovens feministas: sujeitos políticos que entrelaçam questões de gênero e geração? Anais do Encontro da Associação Brasileira de Psicologia Social, 2009. [http://www.abrapso.org.br/siteprincipal/images/Anais_XVENABRAPS O/133.\%20as\%20iovens\%20feministas.pdf - acesso em 03 out. 2019.]

BoIX, Montserrat; Miguel, Ana de. Os gêneros da rede: os ciberfeminismos. In: NATANSHON, Graciela. Internet em Código Feminino: Teorias e Práticas. Buenos Aires, La Crujía Ediciones, 2013, pp. $39-76$ [http://www.genderit.org/sites/default/upload/livrogiga_internet_cod_fe m_ptbr.pdf - acesso em 17 ago. 2016].

BOURDIEU, Pierre. Espaço social e poder simbólico. In: BOURDIEU, Pierre. Coisas Ditas. São Paulo, Brasiliense, 1990, pp.149-168.

BOURDIEU, Pierre. O Poder simbólico. Rio de Janeiro, Bertrand Brasil, 2002. 
Bourdieu, Pierre. A Dominação Masculina. Rio de Janeiro, Bertrand Brasil, 2007.

FAirClough, Norman. Discurso e mudança social. Brasília, Editora da UNB, 2001.

FERREIRA, Carolina Branco de Castro. Feminismos web: linhas de ação e maneiras de atuação no debate feminista contemporâneo. cadernos pagu (44), Campinas, SP, Núcleo de Estudos de GêneroPagu/Unicamp, 2015 , pp.199-228 [http://www.scielo.br/scielo.php?script =sci arttext\&pid $=$ S010483332015000100199\&lng=en\&nrm=iso - acesso em 18 out. 2016].

Foucault, Michel. Microfísica do poder. Rio de Janeiro, Edições Graal, 1979.

Foucault, Michel. A arqueologia do saber. Rio de Janeiro, Forense Universitária, 2008.

GONÇALVES, Eliane; PINTO, Joana Plaza. Reflexões e problemas da "transmissão" intergeracional no feminismo brasileiro. cadernos pagu (36), Campinas, SP, Núcleo de Estudos de Gênero-Pagu/Unicamp, 2011, pp. 25-46. [http://periodicos.sbu.unicamp.br/ojs/index.php/cadpagu/article/view/8 644988 - acesso em: 06 abr. 2017].

LAZAR, Michelle. Recuperating feminism, reclaiming femininity: Hybrid postfeminist I-dentity in consumer advertisements. Gender and Language. Equinox. 8(2), 2014, pp.205-224.

LOVELL, Terry. Thinking Feminism With and Against Bourdieu. Feminist Theory 1(1), 2000, pp.11-32. [https://journals.sagepub.com/doi/10.1177/14647000022229047 acesso em 03 out. 2019]

LOVELL, Terry. Bourdieu, class and gender: "The return of the living dead"? In: AdKINS, Lisa; SkEGGS, Beverley (ed.). Feminism After Bourdieu. Oxford, The Blackwel Publishing/The Sociological Review, 2004, pp.37-56.

MARTEllo, Laura França. A emergência das "jovens feministas" enquanto sujeito político no feminismo brasileiro e suas implicações na configuração do "campo feminista e de gênero". $36^{\circ}$ Encontro 
Anual da ANPOCS. Águas de Lindóia, SP, 2012.[http://anpocs.com/index.php/encontros/papers/36-encontroanual-da-anpocs/gt-2/gt15-2/8012-a-emergencia-das-jovensfeministas-enquanto-sujeito-politico-no-feminismo-brasileiro-e-suasimplicacoes-na-configuracao-do-campo-feminista-e-de-genero/file acesso em 03 out. 2019]

MCNAY, Lois. Gender, Habitus and the Field: Pierre Bourdieu and the Limits of Reflexivity. Theory, Culture and Society 16(1), 1999, pp.175-193.

MCNAY, Lois. Gender and Agency. Reconfiguring the Subject in Feminist and Social Theory. Cambridge, Polity, 2000.

MCNAY, Lois. Agency and experience: gender as a lived relation. In: AdKINS, Lisa; SkEgGS, Beverley (ed.). Feminism After Bourdieu. Oxford, The Blackwel Publishing/The Sociological Review, 2004, pp.75-95.

MCrobBiE, Angela. Post-feminism and popular culture. Feminist Media Studies 4(3), Taylor and Francis, 2004, pp.255-264.

MCROBBIE, Angela. The Aftermath of Feminism: gender, culture and social change. London, Sage, 2009.

MODLESKI, Tania. Feminism without Women: Culture and Criticism in a "Postfeminist" Age. New York, Routledge, 1991.

PESQUISA Instituto Avon e Data Popular: "Violência Contra a Mulher no Ambiente Universitário", 2015 [http://agenciapatriciagalvao.org.br/wpcontent/uploads/2015/12/Pesquisa-Instituto-Avon_V9_FINAL_Bx.pdf - acesso em 29 mar. 2017].

RElatóRIo Final da Comissão Parlamentar de Inquérito constituída pelo Ato $N^{\circ}$ 56, de 2014, São Paulo, ALESP, 2015. [http://www.al.sp.gov.br/repositorio/arquivoWeb/com/com3092. pdf - acesso em 18 mar 2017].

SAFFIOTI, Heleieth. Gênero, patriarcado, violência. São Paulo, Fundação Perseu Abramo, 2015.

SCHARFF, Christina. Repudiating Feminism: Young Women in a Neoliberal World. Farnham and Burlington, Ashgate, 2012. 
SCHARFF, Christina. Gender and Neoliberalism: Exploring the Exclusions and Contours of Neoliberal Subjectivities. Theory, Culture and Society, April 2014. [http://www.theoryculturesociety.org/christinascharff-on-gender-and-neoliberalism/ - acesso em 06 nov. 2016].

ScotT, Joan. Gender and the politics of history. New York, Columbia University Press, 1988.

ZASLOW, Emilie. Feminism, Inc:: coming of age in girl power media culture. New York, Palgrave Macmillan, 2009. 